\title{
Soil Amendments with Sugarcane Bagasse and its Effect on Soil Humic Acid Contents and Chinese Cabbage Growth Components
}

\author{
Mwita Solomon Chacha, Banyikwa Andrew and Maheswara Rao Vegi* \\ Department of Chemistry, School of Physical Sciences, College of Natural and Mathematical Sciences, The University of Dodoma, Tanzania
}

Submission: April 22, 2019; Published: May 08, 2019

"Corresponding author: Maheswara Rao Vegi, The Department of Chemistry, School of Physical Sciences, College of Natural and Mathematical Sciences, The University of Dodoma, Dodoma, P. O. Box: 338, Tanzania

\begin{abstract}
Sugarcane bagasse (SCB) which is a waste byproduct of sugarcane industry can be used as soil amendments to improve crop yield and provide reasonable economic means to recycle these wastes in an environment friendly manner. In this study experiments were conducted to test the rate of production of humic acid during the decomposition of SCB for 30 days and effect of SCB amendments on growth components of Chinese Cabbage (Brassica rapa, subsp. pekinensis). Humic acid were extracted using the classic alkali/acid fractionation method while FT-IR method was used to characterize humic acid. The results were shown that higher amount $(0.2779 \mathrm{~g})$ of humic acid was extracted after 30 days, and small amount $(0.0053 \mathrm{~g})$ was extracted from 0 day of SCB decomposition. The amount of humic acid extracted from SCB is significantly increased with respect to the time for decomposition of SCB. Growth performance of Chinese cabbage was recorded in terms of increase in plant height above ground, fresh and dry weight, root length, root fresh and dry weight. The experiment was conducted by $3 \times 3$ factorial designs employing three concentrations of SCB $(0 \%, 2 \%, 5 \%$ and $10 \%)$. The results showed that there is significant increase in plant growth components with increase of SCB concentration. It is recommended that application of SCB 10\% will result in enhanced yield of Chinese cabbage. This may be due to high amount of humic acid produced by SCB after decomposition which leads to improve other soil characteristics.
\end{abstract}

Keywords: Soil amendment; Sugarcane bagasse; Humic acid; Chinese cabbage (Brassica rapa, subsp. pekinensis); FT-IR

Abbreviations: SCB: Sugarcane Bagasse; HA: Humic Acid; RWC: Relative Water Content; FW: Fresh Weight; TW: Turgid Weight; DW: Dry Weights; PDM: Plant Dry Mass; FRW: Fresh Root Weight; FSW: Fresh Shoot Mass; RDW: Root Dry Weight; SDW: Shoot Dry Weight

\section{Introduction}

The population increase and industrial development produce an enormous amount of organic residues creating great environmental problems now a day. The appropriate agriculture use of these residues can become advantageous for the mankind because it allows nutrients recycling, improve crop production, less pollution problems and as well the improvement of the physical, chemical and biotic conditions of the soil [1]. Organic matter applied to the soil favors the development and growth of plants because it prevents nutrients loss by leaching [2-4]. The sugarcane is a grassy crop that produces, in a short period, a high income of biomass, energy and fibres, being considered one of the plants with larger photosynthetic efficiency [1]. Its plantation in a wide scale is traditional in several countries of the tropical and subtropical regions to produce sugar, alcohol and other bioproducts. Several tons of sugarcane residues are produced and need to be conditioned.
Experiments have been conducted to study the viability of those residues on fish feeds, as nematicide on mandarin culture as horticulture substrate mixes or wheat production [5-8]. Sugarcane bagasse is a source of vegetal fiber that has potential use on the industry of polymeric composites [9]. Sugarcane bagasse (SCB) produce humic acid (HA) after decomposition which have colloidal character and huge active surface which provide fine adsorptive properties [10]. Adsorptive features of HA allow to supply necessary micro-and macronutrients to plants and eliminating from the ground ionic and molecular impurities in the form of heavy metals $[10,11]$. All these potential uses have the major goal of resolving the disposal problems of sugarcane residues. The main objective of this study is to quantify the amount of HA produced after amending the soil with SCB with respect to the entire life span of growing plant Chinese cabbage (Brassica rapa, subsp. pekinensis). 


\section{Materials and Methods}

\section{Mode of collection and preparation of soil and sugarcane bagasse samples}

The composite sampling method was used for sampling, where about 25 subsamples of each $2 \mathrm{kgs}$ collected from Ngongona villege in Dodoma region and a composite sample of $50 \mathrm{kgs}$ used in this study. Samples were collected with the help of an auger from the $10 \mathrm{~cm}$ depth and kept in plastic bags and packed in the bucket [12]. Soil samples were air dried on dry wood which act as drying surface. $20 \mathrm{kgs}$ of sugarcane bagasse was collected from local sugarcane juice vendors (Ngongona sugarcane juice extracts) manually by using hands processed before use. The sugarcane sample was air dried for four days and then dried in an oven at $70^{\circ} \mathrm{C}$ for two consecutive days. Finally grounded by using blender and sieved (2mm mesh) to make fine powder [13].

\section{Extraction of humic acid}

SCB amended (50:50) soil $(10 \mathrm{~g})$ was mixed with $5 \mathrm{~mL}$ of distilled water allowed decomposing at $37{ }^{\circ} \mathrm{C}$. Four samples were prepared in the same manner and allowed to decompose at different periods $(0,10,20$ and 30 days). Humic acids were extracted using the classic alkali/acid fractionation method [14]. The SCB amended soil was digested in 0.1 N KOH $(1: 10 \mathrm{~W} / \mathrm{v})$ for 24 hours at room temperature $\left(23 \pm 2{ }^{\circ} \mathrm{C}\right)$. The undigested bulk residue from SCB compost was then separated from the solute fraction by centrifugation at 5000rpm for 30 minutes followed by vacuum filtration through a glass filter paper. The filtered supernatant was acidified to $\mathrm{pH} 2$ with $6.0 \mathrm{~N} \mathrm{H}_{2} \mathrm{SO}_{4}$ and kept in a cold room in the dark for $24 \mathrm{hrs}$ in order to obtain flocculation of humic acids. After acidification, the humic precipitate (humate) was collected by centrifuging at $5000 \mathrm{rpm}$ for $30 \mathrm{~min}$, washed three times with distilled water to remove residual $\mathrm{H}_{2} \mathrm{SO}_{4}$, freeze-dried and brown powder was obtained for each treatment which was used for FT-IR to characterize humic acid.

\section{Experimental set up and treatments for growing Chinese cabbage}

Table 1: List of treatment combinations.

\begin{tabular}{|c|c|c|}
\hline Treatment & Treatment & Description \\
\cline { 1 - 2 } Code & Combinations & \\
\hline C(control) & $\mathrm{B}_{0} \mathrm{~S}_{100}$ & $100 \%$ Soil without Bagasse \\
\hline $\mathrm{B}_{1}$ & $\mathrm{~B}_{2} \mathrm{~S}_{98}$ & $98 \%$ Soil with $2 \%$ Bagasse \\
\hline $\mathrm{B}_{2}$ & $\mathrm{~B}_{5} \mathrm{~S}_{95}$ & $95 \%$ Soil with $5 \%$ Bagasse \\
\hline $\mathrm{B}_{3}$ & $\mathrm{~B}_{10} \mathrm{~S}_{90}$ & $90 \%$ Soil with $10 \%$ Bagasse \\
\hline
\end{tabular}

The experiment was carried out at College of Natural and Mathematical Sciences, The University of Dododma, Dodoma, Tanzania from Mid-May to July 2018. This experiment employed quasi-experimental method using four treatments. Each treatment has potted plants composed of three sample plants per pot $(3.5 \mathrm{~kg})$ in triplicate making a total of 12 pots. The collected soil was mixed thoroughly to form homogeneous mixture in different concentrations $(0,2,5$ and 10\%) of SCB (Table 1). For proper decomposition, SCB was applied one month prior to seed planting in the field since the rate of decomposition is affected by temperature, moisture, population and diversity of soil microorganisms [15].

\section{Field management}

Chinese cabbage seeds were germinated following the recommended practice in the soil with different treatments (Table 1). One pot has three sample plants. Plants were watered with $100 \mathrm{~mL}$ for the first 3 days to check the response of pot treatments. Additional $50 \mathrm{~mL}$ of water was administered, depending on the response of the plants to respective pot treatments (Table 2), but equal amount of water $(150 \mathrm{~mL})$ was administered for every plant, using graduated cylinder. To control pests and diseases, the use of contact insecticide (cypermethrin) available in the market was done. It was sprayed following the prescribed dosage $(2 \mathrm{~mL}$ per a liter of water) of the manufacturer.

Table 2: Irrigation scheduling practice to the different treatments $\mathrm{C}(0 \%$ SCB \& $100 \%$ soil), $B_{1}$ ( $2 \%$ SCB \& $98 \%$ soil), $B_{2}$ ( $5 \%$ SCB \& $95 \%$ soil), $\mathrm{B}_{3}(10 \%$ SCB \& $90 \%$ soil).

\begin{tabular}{|c|c|}
\hline Treatment Code & Time (hours) Before Next Irrigation \\
\hline $\mathrm{C}$ & 12 \\
\hline $\mathrm{B}_{1}$ & 48 \\
\hline $\mathrm{B}_{2}$ & 48 \\
\hline $\mathrm{B}_{3}$ & 96 \\
\hline
\end{tabular}

\section{Data collection and analysis}

Agronomy and physiological data of Chinese cabbage growth were collected as indicated below for different treatments (Figure 1) and analyzed by Microsoft excel.

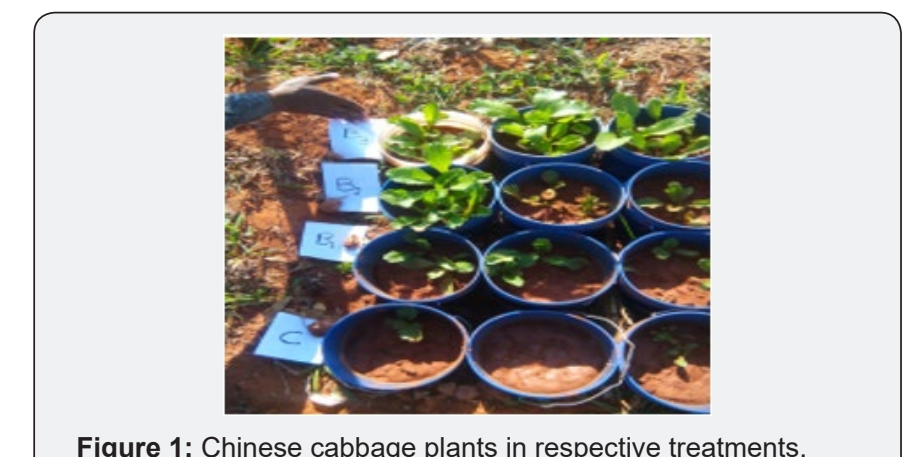

Figure 1: Chinese cabbage plants in respective treatments

\section{Agronomic parameters}

Days to emergence: This parameter of the Chinese cabbage was determined by counting the number of days from sowing to the time when $50 \%$ of the plants started to emerge the tip of panicles through visual observation.

Plant height and root length: Plant height was measured at maturity from the ground level to the top of the Chinese cabbage from each treatment and for selected three plants and the average was taken as plant height $(\mathrm{cm})$. Root length also studied to the same plant for which plant height was determined. 
Number of leaves per plant: Number of leaves were counted from three representative plants from each pot and averaged as per plant.

\section{Physiological parameters}

Plant samples were collected at 5 weeks after sowing. Chinese cabbage plants were separated into leaves and roots for determining relative water content, plant dry mass, root to shoot ratio.
Relative water content (RWC): Fully expanded youngest leaves were selected from different plants from each treatment (Figure 2). Five leaves were sampled and weighed immediately to determine the fresh weight (FW). Then immersed in distilled water in Petri-dishes for $24 \mathrm{~h}$ in darkness and then turgid weight (TW) was determined. The leaves were dried in an oven at $70^{\circ} \mathrm{C}$ for $24 \mathrm{~h}$ and the dry weights (DW) were obtained [16]. From the obtained data, relative water content was calculated using the following formula:

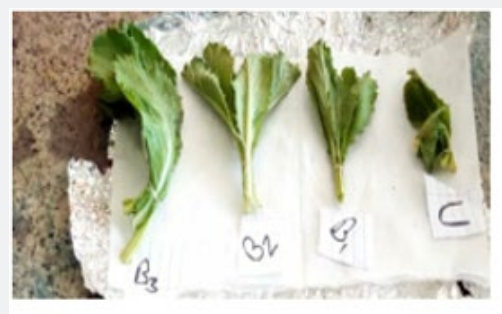

(A)

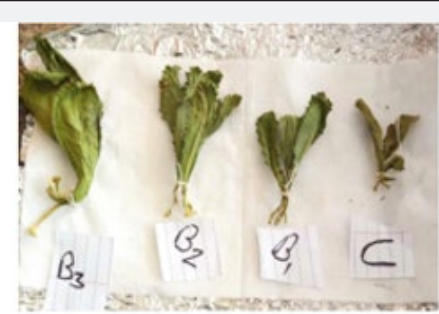

(B)

Figure 2: Youngest leaves collected from different plants for each treatment (A) Fresh leaves (B) Dry leaves.

$$
\text { Relative Water Content }(R W C)=\frac{F W-D W}{T W-D W} \times 100
$$

Plant dry mass: Three Chinese cabbage plants from each treatment were separated into shoot and roots. Then washed in tap water to remove the soil particles and blotted to dry on paper towels. The shoots were weighed by using an electronic weighing balance to determine the fresh weight (FW). Then shoots were dried in an oven at $70^{\circ} \mathrm{C}$ for 24 hours and the dry weight (DW) was obtained. The plant dry mass was calculated by using following formula.

$$
\text { Plant Dry Mass }(P D M)=\frac{F W-D W}{F W} \times 100
$$

Root to shoot ratio: The above ground part (shoot) and below ground part (root) of Chinese cabbage from each treatment were sampled from the plant which is grown very well. The roots were washed in tap water to remove the soil particles and blotted to dry

Table 3: Humic acid extracted from soil amended with SCB on paper towels. The fresh weight was determined immediately after harvesting using an electronic weighing balance. The collected samples of shoots and roots were dried in an oven at 70 ${ }^{\circ} \mathrm{C}$ for 24 hours to obtain dry weight. Then root to shoot ratio was calculated by using formula below [17].

$$
\text { Root to shoot ratio }\left(\frac{R}{S} \text { ratio }\right)=\frac{\text { Weight of dry root }}{\text { Weight of dry shoot }}
$$

\section{Results and Discussion}

The amounts of humic acid extracted from SCB after decomposition at different periods were shown in Table 3. Higher amount $(0.2779 \mathrm{~g})$ of HA was extracted after 30 days, and small amount $(0.0053 \mathrm{~g})$ was extracted from 0 day of SCB decomposition. The amount of HA extracted from soil with SCB is significant with respect to the time taken for decomposition of SCB. The humic acid content of soil with SCB is proportional to the degree of decomposition of SCB [3].

\begin{tabular}{|c|c|c|}
\hline Treatment Code & Days After Decay of SCB in the Soil & HA (g) \\
\hline $\mathrm{C}$ (control) & & 0.0033 \\
\hline $\mathrm{B}_{50 \%} \mathrm{~S}_{50 \%}$ & 0 & 0.0053 \\
\hline $\mathrm{B}_{50 \%} \mathrm{~S}_{50 \%}$ & 10 & 0.0303 \\
\hline $\mathrm{B}_{50 \%} \mathrm{~S}_{50 \%}$ & 15 & 0.1888 \\
\hline $\mathrm{B}_{50 \%} \mathrm{~S}_{50 \%}$ & 30 & 0.2779 \\
\hline
\end{tabular}

\section{B50\%S50\% $=50 \%$ SCB mixed with $50 \%$ soil.}

\section{Characterization of humic acid using FTIR spectra}

Figure 3 shows the FTIR spectra of the humic acid samples collected at $0,10,15,30$ days. In general, all spectra are almost similar in the position of the main bands, but some differences can be observed in their relative intensity. All the spectra showed bands that could be assigned to the main groups, as: $3371.74-$ $3335.45 \mathrm{~cm}^{-1}$ the intense and broad absorption band due to $\mathrm{O}-\mathrm{H}$ bond stretching which mainly belongs to the carboxylic acids involved in hydrogen bonding. The week and narrow bands at 2930.99-2854.66 $\mathrm{cm}^{-1}$ for HA extracted from zero and ten days 
after decomposition of SCB was due to symmetric stretching bands of aliphatic $\mathrm{C}-\mathrm{H}$ bonds of $-\mathrm{CH}_{3},-\mathrm{CH}_{2}$ - and tertiary $\mathrm{C}-\mathrm{H}$. The

obtained absorption band is very similar to that from soil HA which is reported by Stevenson [3].

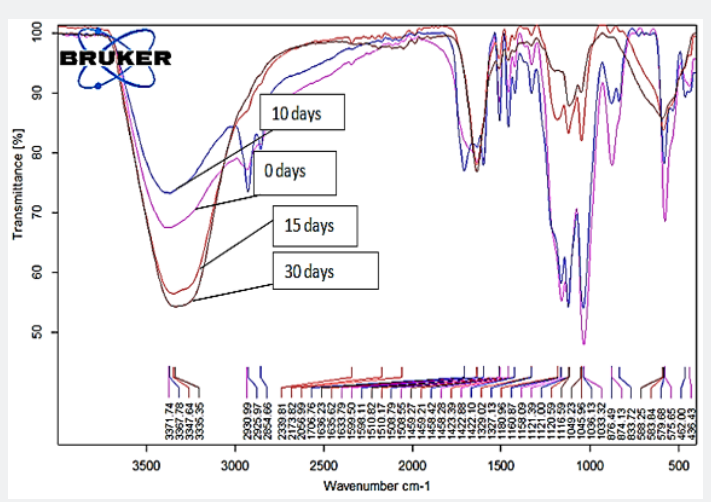

Figure 3: IR spectra of humic acid extracted from decomposition of SCB after different period.

It is possible to differentiate the source and the humification condition of the organic matter by using FT-IR spectrum. The HA with relatively low degree of humification has a spectrum with $-\mathrm{CH}_{3}$ and $-\mathrm{CH}_{2}-$ and tertiary $\mathrm{C}-\mathrm{H}$ absorption bands (generally located around $2900-2850 \mathrm{~cm}^{-1}$ ). It is clearly observed that these bands are absent or overlapped with $\mathrm{O}-\mathrm{H}$ band of $\mathrm{COOH}$ group in the spectra of HA samples collected at 15 and 30 days of decomposition of SCB. Moreover, the band intensity of carboxylic $\mathrm{O}-\mathrm{H}$ groups increased with the number of days of decomposition of SCB. This implies as the decomposition period increases the number of carboxylic acid groups increased. Hence it is proved that more humic acid produced with more number of days of decomposition of SCB. The sharp and medium intense bands $\left(1633.79,1706.76,1635.62\right.$ and $1636.23 \mathrm{~cm}^{-1}$ for $0,10,15$ and 30 days respectively) observed in the carbonyl region also indicates the production of humic acid with the decomposition of SCB. A pair of bands observed between $1598.11-1450 \mathrm{~cm}^{-1}$ (for $\mathrm{C}=\mathrm{C}$ ) indicate the presence of aromatic ring in humic acid. The results were slightly similar with the results reported by Reddy and his co-workers (2018) on FTIR spectrum of HA of paddy soils [18].

\section{Effects of SCB on agronomic parameters of Chinese cabbage}

Days to seed emergency: Days to emergence generally took 3 to 5 days. The plants emerged fast from the soil mixed with $10 \%$ of SCB (Treatment $\mathrm{B}_{3}$ ). Faster germination from $\mathrm{B}_{3}$ treated pot might be due to SCB amendment germination. In order to emerge the plants from $50 \%$ of seeds it took only three days in the case of soil with $10 \%$ of SCB whereas it took five days in the case of soil without any SCB (control). With the increase in the percentage of SCB from 0 to $10 \%$ the plant emergence from $50 \%$ of seeds took a smaller number of days (Table 4). The absorption of humic substances produced by SCB into seeds has a positive influence on seed germination and seedling development. Availability of humic (HA) or fulvic acids (FA) to seeds will increase the seed germination, resulting in higher seed germination rates [19]. Results of this study are similar with the findings of Eyheraguibel [20]. According to their study the germination was started 3 days after sowing and the first daily count of germinated seed showed more radicle emergence from the soil with humic like substances. Stehouwer and Macneal [21] recorded an increase of germination and fescue seedling establishment after the first leaching event as a response of the salt decrease following compost amendment [21].

Table 4: Effect of SCB on days of seed emergency (DSE), plant height, root length, number of leaves and leaf area of Chinese cabbage.

\begin{tabular}{|c|c|c|c|c|}
\hline $\begin{array}{c}\text { Treatment } \\
\text { Code }\end{array}$ & DSE/Plant & $\begin{array}{c}\text { Plant } \\
\text { Height } \\
\text { (cm) }\end{array}$ & $\begin{array}{c}\text { Root } \\
\text { Length } \\
\text { (cm) }\end{array}$ & $\begin{array}{c}\text { Number of } \\
\text { Leaves }\end{array}$ \\
\hline $\mathrm{C}$ & 5 & 5.3 & 2.2 & 3.6 \\
\hline $\mathrm{B}_{1}$ & 4 & 7.9 & 3.5 & 6 \\
\hline $\mathrm{B}_{2}$ & 3 & 10.1 & 4.1 & 7.8 \\
\hline $\mathrm{B}_{3}$ & 3 & 15.8 & 6.2 & 8.7 \\
\hline
\end{tabular}

Plant height and root length: Plant height increased from 5.3 to $15.3 \mathrm{~cm}$ with the increase in the percentage of SCB in the soil from 0 to $10 \%$. This indicates the increase in growth of the plant in soil amended with SCB. This might be due to increase in the amount of humic acid and organic carbon in the soil after amendment with SCB. The tallest root length $(6.2 \mathrm{~cm})$ was observed in the soil amended with $10 \%$ of SCB (treatment $\mathrm{B}_{3}$ ) and the shortest root length $(2.2 \mathrm{~cm})$ was obtained from the control (Table 4). For treatment $\mathrm{B}_{3}$ the amended organic matter improves the physical properties of the soil and causes increase of root development which helps the uptake of more water and nutrients [22]. Both plant height and root length increased significantly with the increase in the percentage of SCB in the soil. The significant increase might be from soil properties that support the root growth due to the enough oxygen diffusion to the root tip and supply of enough water for root growth. The results of this study are like that of reported by Robert \& Ronny [22] that after application of organic matter, soil sodium adsorption ratio declines $56 \%$, and root length of plant increases $140 \%$. Sodium induces soil structural deterioration (slaking, aggregate destruction, and clay and organic colloid dispersion), leading to subsequent water infiltration and percolation problems [22]. 
Number of leaves in plant: The average number of leaves per plant was found highest (8.7) in the soil with $10 \%$ of SCB and lowest (3.6) was in the control (Table 4). The average number of leaves of Brassica rapa, subsp. Pekinensis growing in soil with different concentration of SCB reveals an overall increasing pattern from control to $\mathrm{B}_{3}(10 \% \mathrm{SCB})$. This might be due to improvement in the soil properties to increase soil fertility, water holding capacity and soil porosity etc. to support the plant growth. SCB when applied to land increases soil fertility by providing macro nutrients such as nitrogen and phosphorous and micronutrients such as $\mathrm{Zn}$ and $\mathrm{Cu}[22]$.

\section{Effect of SCB on physiological parameters of Chinese cabbage}

Table 5: Effect of SCB amended soil on plant biomass, relative water contents, root and shoot dry matter and root to shoot ratio of Chinese cabbage plant.

\begin{tabular}{|c|c|c|c|c|c|c|c|}
\hline \multirow{2}{*}{$\begin{array}{l}\text { Treatment } \\
\text { Code }\end{array}$} & \multirow{2}{*}{ RWC } & \multirow{2}{*}{ PDM } & FRW & \multirow{2}{*}{ FSW } & RDW & \multirow{2}{*}{ SDW } & \multirow{2}{*}{$\begin{array}{c}\text { Root to Shoot } \\
\text { Ratio }\end{array}$} \\
\hline & & & g/plant & & g/plant & & \\
\hline $\mathrm{C}$ & 57.29 & 87.8 & 0.957 & 1.361 & 0.096 & 0.402 & 0.24 \\
\hline $\mathrm{B}_{1}$ & 72.24 & 88.95 & 1.871 & 2.24 & 0.108 & 1.017 & 0.11 \\
\hline $\mathrm{B}_{2}$ & 72.25 & 89.01 & 2.056 & 3.987 & 0.197 & 1.97 & 0.1 \\
\hline $\mathrm{B}_{3}$ & 73.21 & 90.94 & 5.461 & 8.512 & 0.203 & 2.632 & 0.08 \\
\hline
\end{tabular}

RWC = Relative Water Contents; PDM = Plant Dry Mass; FRW = Fresh Root Weight; FSW = Fresh Shoot Mass; RDW = Root Dry Weight; SDW = Shoot Dry Weight.

Relative water content: Relative water content (RWC) is the most appropriate measure of plant water status in terms of the physiological consequence of cellular water deficit. Water potential as an estimate of the energy status of plant water is useful in dealing with water transport in the soil-plant-atmosphere continuum. However, it does not account for osmotic adjustment. For the same leaf water potential two different cultivars can have different leaf RWC, indicating a corresponding difference in leaf hydration, leaf water deficit and physiological water status. Hence RWC is an appropriate estimate of plant water status in terms of cellular hydration under the possible effect of both leaf water potential and osmotic adjustment [23]. From the data in Table 5, relative water content increased significantly from 57.29 to 73.21 , when SCB increased from 0 to $10 \%$ in the soil (treatments C $(0 \%$ $\mathrm{SCB})$ to $\left.\mathrm{B}_{3}(10 \% \mathrm{SCB})\right)$.
Plant dry mass and fresh weight: Results presented in Table 5 shows that the fresh weights of root and shoot ( $g$ per plant) significantly increased with increase in the SCB content in the soil from 0 to $10 \%$ (treatments from $C, B_{1}, B_{2}$ and $B_{3}$ respectively). Furthermore, dry shoot and root biomass of the plant were significantly enhanced in the soil with SCB as compared to the soil without SCB (control). The root/shoot ratio also enhanced due to soil amendment with SCB comparing with the control (Figure 4). The observed enhancement of plant growth by the application of SCB to the soil is due to increase in uptake of the elements such as $\mathrm{N}, \mathrm{P}, \mathrm{K}, \mathrm{Fe}, \mathrm{Zn}$, and Mn nutrients [24]. Moreover, enhancement of photosynthesis, plant root respiration has resulted in greater plant growth with HA produced by SCB [25]. The performance of the soil in the plant growth after the application of SCB was due to enhancement in moisture retention and the improvement of nutrients supply in the root zone [26].

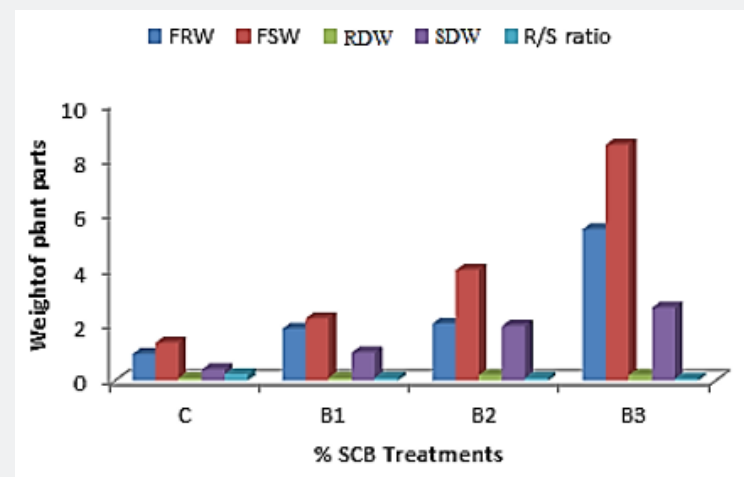

Figure 4: Effect of SCB amended soil on fresh and dry weights of roots and shoots and root to shoot ratio.

\section{Conclusion}

Sugarcane bagasse is generally considered as an agricultural waste product; however, the present findings show it contains enough amounts humic acid after decomposition. Application of different levels of sugarcane bagasse positively influenced most of the yield parameters of Chinese cabbage (Brassica rapa, subsp. pekinensis). Crop improved in response to its favorable effects on the soil characteristics. Utilization of sugarcane bagasse as organic 
fertilizer can save chemical fertilizers along with minimizing environmental pollution. By comparing the levels of sugarcane bagasse application in this study, $10 \%$ was suggested to be the standard dose due to best yield parameters such as the root and shoot length of plant, root and shoot dry weight of plant, number of leaves and relative water content of Chinese cabbage (Brassica rapa pekinensis) crop in the soil amended with SCB.

\section{References}

1. Brito J, Chada I, Pinto P, Guerrero C, Beltrao J (2007) Use of sugarcane pulp residue as a organic amendment and its possible use as a horticultural substratum. Proceedings of the $3^{\text {rd }}$ IASME/WSEAS Int. Conf. on Energy, Environment, Ecosystems and Sustainable Development, Agios Nikolaos, Greece.

2. Kiehl EJ (1985) Fertilizantes Organicos. Agronomica Ceres, Sao Paulo, Portuguese, pp. 492.

3. Stevenson FJ (1994) Humus Chemistry: Genesis, Composition, Reactions, ( $2^{\text {nd }}$ edn), John Wiley \& Sons, New York, pp. 512.

4. Kaushal JR, Kakkar VK, Malik NS, Makkar GS (1980) Chemical composition of sugarcane bagasse and filter-mud and the effect of source and alkali treatment on the in vitro dry matter digestibility of bagasse. Indian Journal of Dairy Science 34: 458-462.

5. Badr MA, Badran NM (2001) Effect of some composted residues and urea fertilization on wheat yield. Annals of Agricultural Science 39(1): 707-716.

6. Fermino MH, Kampf TN (2003) Use of the bom Jesus soil with organic conditioners as horticultural substrates for plants. Pesq. Agrop. Ga/Cha 9(1-2): 33-41.

7. El-Nagdi WMA, Youssef MMA (2004) Sugarcane residues soil amendments for crop improvement and citrus nematode Tylenchulus semipenetrans management on mandarin under sandy (calcareous) soil conditions. Egyptian Journal of Agricultural Research 82(2 Suppl): 11-25.

8. Ulloa JB, van Weerd JH, Huisman EA, Verreth JAJ (2004) Tropical agricultural residues and their potential uses in fish feeds: the Costa Rican situation. Waste Manag 24(1): 87-97.

9. Paiva JMF, Trindade WG, Frollini E, Pardini LC (2004) Carbon fiber reinforced carbon composites from renewable sources. PolymerPlastics Technology and Engineering, 43(4): 1187-1197.

10. Skybova M, Turcaniova L, Cuvanova S, Zubrik A, Hredzak S, Hudymacova LJ (2007) Mechanochemical activation of humic acids in the brown coal. Journal of Alloys and Compounds 434(1435): 842-845.

11. Abramov EG, Bezzubov AA (2007) Electrosorptive separation of humic substances. Journal of Water Chemistry and Technology 29(3): 125130.
12. Walworth JL (2006) Soil sampling and analysis. University of Arizona Cooperative Extension, USA, p. 5.

13. Bhushan G (2016) Impact of bagasse ash amended soil on growth and yield of Pisum sativum. Research Journal of Pharmaceutical, Biological and Chemical Sciences 7(1): 448-456.

14. Atiyeh RM, Lee S, Edwards CA, Arancon NQ Metzger JD (2002) The influence of humic acids derived from earthworm-processed organic wastes on plant growth. Bioresource Technol 84(1): 7-14.

15. Liwayway HA (2013) Growth response of Brassica rapa on the different wavelength of light. International Journal of Chemical Engineering and Applications 4(6): 415-418.

16. Silveira JA, Viegas Rde A, Da Rocha IM, Moreira AC, Moreira RdeA, et al. (2003) Proline accumulation and glutamine synthetase activity are increased by salt induced proteolysis in cashew leaves. J Plant Physiol 160(2): 115-123.

17. Askari Y, Soltani A, Akhavan R, Tahmasebi Kohyani P (2017) Assessment of root-shoot ratio biomass and carbon storage of Quercus brantii lindl. in the central Zagros forests of Iran. Journal of Forest Science 63(6): 282-289.

18. Schnitzer M (1999) Lifetime perspective on the chemistry of soil organic matter. Advances in Agronomy 68: 1-30.

19. Pettit RE (2004) Organic matter, humus, humate, humic acid, fulvic acid and humin: Their importance in soil fertility and plant health. p. 17.

20. Eyheraguibel B, Silvestre J, Morard P (2008) Effects of humic substances derived from organic waste enhancement on the growth and mineral nutrition of maize. Bioresource Technology 99(10): 4206-4212.

21. Stehouwer RC, Macneal K (2003) Use of yard trimming compost for restoration of saline soil incineration ash. Compost Science and Utilization 11(1): 51-60.

22. Robert NC, Ronny RD (2012) Best management practices for Saline and sodic turfgrass soils: Assessment and reclamation. ( $1^{\text {st }} \mathrm{edn}$ ), CRC Press: Taylor \& Francis Group, Boca Raton London, New York, pp. 496.

23. Barrs HD, Weatherley PE (1962) A re-examination of the relative turgidity techniques for estimating water deficits in leaves. Australian Journal of Biological Sciences 15: 413-428.

24. Selim EM, Mosa AA (2012) Fertigation of humic substances improves yield and quality of broccoli and nutrient retention in a sandy soil. Journal Plant Nutrition and Soil Science 175(2): 273-281.

25. Gad El Hak SH, Ahmed AM, Moustafa YMM (2012) Effect of foliar application with two antioxidants and humic acid on growth, yield and yield components of peas (Pisum sativum L.). Journal of Horticultural Science \& Ornamental Plants 4(3): 318-328.

26. Sanga D (2013) Evaluation of soil fertility status and optimization of its management in sesame (Sesamum indicum L.) growing areas of Dodoma district. Sokoine University of Agriculture, Tanzania, pp. 3738. 

CC Commons Attribution 4.0 License
Col: 10.19080/ARTOAJ.2019.21.556166

\section{Your next submission with Juniper Publishers} will reach you the below assets

- Quality Editorial service

- Swift Peer Review

- Reprints availability

- E-prints Service

- Manuscript Podcast for convenient understanding

- Global attainment for your research

- Manuscript accessibility in different formats (Pdf, E-pub, Full Text, Audio)

- Unceasing customer service

Track the below URL for one-step submission https://juniperpublishers.com/online-submission.php 